Article

\title{
Effect of Lysosomal Cathepsin L on Proteolysis of Beef Myofibrillar Proteins In Vivo and In Vitro
}

\author{
Baowei Cui ${ }^{1,+}$, Xiuyun Guo ${ }^{2,3, *,+}$, Yawei Zhang ${ }^{4}$ and Xiangren Meng ${ }^{2,3}$ \\ 1 Faculty of Food Science and Technology, Suzhou Polytechnic Institute of Agriculture, Suzhou 215008, China; \\ cuibaow110@126.com \\ 2 School of Tourism and Cuisine, Yangzhou University, Yangzhou 225127, China; xrmeng@yzu.edu.cn \\ 3 Key Laboratory of Chinese Cuisine intangible Cultural Heritage Technology Inheritance, Ministry of Culture \\ and Tourism, Yangzhou 225127, China \\ 4 National Center of Meat Quality and Safety Control, College of Food Science and Technology, Nanjing \\ Agricultural University, Nanjing 210095, China; zhangyawei@njau.edu.cn \\ * Correspondence: 007840@yzu.edu.cn \\ + These authors contributed equally to this work.
}

Citation: Cui, B.; Guo, X.; Zhang, Y.; Meng, X. Effect of Lysosomal Cathepsin L on Proteolysis of Beef Myofibrillar Proteins In Vivo and In Vitro. Foods 2022, 11, 613. https:// doi.org/10.3390/foods11040613

Academic Editor: Piero Franceschi

Received: 17 January 2022

Accepted: 17 February 2022

Published: 21 February 2022

Publisher's Note: MDPI stays neutral with regard to jurisdictional claims in published maps and institutional affiliations.

Copyright: (C) 2022 by the authors. Licensee MDPI, Basel, Switzerland. This article is an open access article distributed under the terms and conditions of the Creative Commons Attribution (CC BY) license (https:// creativecommons.org/licenses/by/ $4.0 /)$.

\begin{abstract}
This study investigated the effects of cathepsin L on proteolysis of beef myofibrillar proteins in vivo and in vitro. Results indicated that cathepsin L affected the degradation of desmin and troponin-T during postmortem aging, and the extent of degradation increased from $1 \mathrm{~d}$ to $14 \mathrm{~d}$ postmortem. No detectable degradation of titin, nebulin, and $\alpha$-actinin in the presence of cathepsin $\mathrm{L}$ inhibitor was observed during postmortem aging. In vitro, cathepsin $\mathrm{L}$ affected the degradation of titin, nebulin, and troponin- $\mathrm{T}$, and the extent of degradation increased with increasing incubation time. Nevertheless, cathepsin L did not cause the degradation of $\alpha$-actinin and desmin, regardless of incubation temperature. The different results between in vitro and in vivo experiments might mainly depend on different treatment temperatures. Overall, these results indicated that cathepsin L participated in the degradation of myofibrillar proteins and meat tenderization.
\end{abstract}

Keywords: cathepsin L; proteolysis; tenderness; beef; western blotting

\section{Introduction}

Tenderness is generally considered to be the most important sensorial attribute for consumers regarding meat consumption [1,2]. Therefore, improving the tenderness of meat is an important issue in the meat industry [3]. Meat tenderness is mainly determined by the proteolysis of key myofibrillar and cytoskeletal proteins, such as titin, nebulin, $\alpha$-actinin, desmin, troponin-T, dystrophin, and vinculin during the postmortem aging [4-6] Endogenous proteolytic enzymes (e.g., calpains, caspases, and lysosomal proteinases) are of crucial importance for the postmortem proteolysis of the key myofibrillar and cytoskeletal proteins, and thus, in meat tenderization [7,8]. Cathepsins, which are located in the lysosomes of muscle cells, and potentially released during postmortem aging, are favored by postmortem cells, and play an important role in proteolysis and meat tenderization [9].

However, the effect of cathepsins on meat tenderness varies considerably among studies. Previous studies have shown that cathepsin L (CAT) can degrade myofibrillar proteins (MPs) in vitro [8,10]. Myosin heavy chain (MHC), $\alpha$-actinin, actin, troponin-T, and troponin-I assembled in rabbit myofibrils are degraded by CAT at $37^{\circ} \mathrm{C}$ according to the study by Matsukura et al. [11]. Mikami et al. [12] also find that CAT hydrolyzed most myofibrillar proteins, including titin, nebulin, troponin-T, and tropomyosin in beef, rabbit, and chicken myofibrils in vitro. Nevertheless, several studies have shown that CAT has no effect on MPs proteolysis and meat tenderness in vivo. For instance, the results of Uytterhaegen et al. [9] indicate that CAT plays no significant role in MPs degradation at $2{ }^{\circ} \mathrm{C}$ during $8 \mathrm{~d}$ postmortem. In addition, Koohmaraie et al. [13] also conclude, from 
sodium dodecyl sulphate-polyacrylamide gel electrophoresis (SDS-PAGE) patterns, that CAT has no contribution to the degradation of MPs. The different treatment temperatures seem to be responsible for the contradictory results of MPs degradation by CAT in vivo and in vitro. Nevertheless, this hypothesis has yet to be verified. Therefore, to understand the role of CAT in meat tenderness, it is necessary to explore the effect of CAT on proteolysis both in vivo and in vitro.

The aim of the present study was to investigate the effect of CAT on the proteolysis of MPs both in vivo and in vitro.

\section{Materials and Methods}

Purified CAT from a bovine pancreas was used to examine the effect of CAT on beef myofibrils at different temperatures in vitro, and selective CAT inhibitor was chosen to investigate the degradation of CAT on bovine skeletal muscle protein during postmortem aging.

\subsection{In Vivo Experiments}

\subsubsection{Sample Preparation}

Three 2.5 years old Simmental Crossbred cattle (live weight $428 \pm 38 \mathrm{~kg}$ ) were selected from a farm at Hebei Fucheng Food Co., Ltd (Yanjiao, China). After $24 \mathrm{~h}$ of rest, they were humanely slaughtered on the basis of the Operating Procedures of Cattle Slaughter in the National Standards of China. At approximately 30-45 min after exsanguination, the longissimus thoracis muscles (from 5 th lumbar vertebrae to 12 th thoracic vertebrae) were removed from the carcass, and excess fat was trimmed. About $100 \mathrm{~g}$ of muscle was collected as 0 day samples, and immediately frozen in liquid nitrogen, and stored until subsequent analysis. Approximately $120 \mathrm{~g}$ of muscle was cut into small pieces, and divided into three groups (ca. $40 \mathrm{~g}$ /group). Each group of muscle was then subdivided into four fractions (ca. $10 \mathrm{~g} /$ fraction), and soaked in the following treatment buffer, in the ratio of 1:1 (w/v) (meat/solution): (1) control: $60 \mathrm{mM} \mathrm{NaCl}$ and $2 \mathrm{mM} \mathrm{NaN}_{3}$ (C); (2) control $+100 \mu \mathrm{M}$ cathepsin L inhibitor (CATI, Sigma-Aldrich, Milwaukee, WI, USA), and then stored for 1, 3, 7 , and 14 day at $4{ }^{\circ} \mathrm{C}$. Afterwards, samples were collected individually, and snap-frozen in liquid nitrogen, and then stored at $-80^{\circ} \mathrm{C}$ until required.

\subsubsection{Extraction of MPs}

MPs were extracted according to the method described by Huang et al. [14], with some modifications. Samples were processed at $0-4{ }^{\circ} \mathrm{C}$ to minimize the proteolysis or protein denaturation. Briefly, about $1.0 \mathrm{~g}$ of minced muscle was homogenized in $8 \mathrm{~mL}$ of PRB buffer (100 mM KC1, 2 mM MgCl, 2 mM EDTA, $1 \mathrm{mM}$ DTT, $1 \mathrm{mM} \mathrm{NaN} 3,2 \mathrm{mM}$ $\mathrm{Na}_{4} \mathrm{P}_{2} \mathrm{O}_{7}$, and $10 \mathrm{mM}$ Tris-maleate, $\mathrm{pH} 6.8,4{ }^{\circ} \mathrm{C}$ ) using a polytron at a speed of $14,000 \mathrm{rpm}$ for $30 \mathrm{~s}$, with an interval of $15 \mathrm{~s}$ between bursts. After being centrifugated at $1000 \times g$ for $10 \mathrm{~min}$, the supernatant was decanted, and the pellet was resuspended in $10 \mathrm{~mL}$ of low salt buffer (100 mM KC1, $2 \mathrm{mM} \mathrm{MgCl}_{2}, 2 \mathrm{mM}$ EDTA, $1 \mathrm{mM} \mathrm{DTT}, 1 \mathrm{mM} \mathrm{NaN}$, and $10 \mathrm{mM}$ Tris-maleate, $\mathrm{pH} 6.8,4^{\circ} \mathrm{C}$ ). Then, the centrifugation and resuspension processes were repeated six times. Finally, the pellet was washed twice with $10 \mathrm{~mL}$ Tris-EDTA buffer $\left(10 \mathrm{mM}\right.$ Tris- $\mathrm{HCl}$ and $5 \mathrm{mM}$ EDTA, $\left.\mathrm{pH} 8.0,4^{\circ} \mathrm{C}\right)$. The protein concentration was determined using the BCA Protein Assay Kit.

MPs extracted from different samples were immediately diluted to $6 \mathrm{mg} / \mathrm{mL}$, and then mixed with buffer (30 mM Tris-HCl, $3 \mathrm{mM}$ EDTA, 3\% SDS, 20\% glycerol, 8\% 2mercaptoethanol, and $0.04 \%$ Bromophenol blue, $\mathrm{pH} 8.0)$ at a ratio of 1:1 (v/v). Next, the samples were heated in a $50{ }^{\circ} \mathrm{C}$ water bath for $20 \mathrm{~min}$, and then centrifuged at $10,000 \times g$ for $20 \mathrm{~min}$ at $4^{\circ} \mathrm{C}$. Finally, samples were stored at $-80^{\circ} \mathrm{C}$ for SDS-PAGE and western blotting. 


\subsection{In Vitro Experiments}

\subsubsection{Preparation of CAT}

CAT was purified from a bovine pancreas according to the procedure reported by Li et al. [15], with little modification. Fat and connective tissue were removed from a fresh bovine pancreas at $4{ }^{\circ} \mathrm{C}$. The minced bovine pancreas was homogenized with four volumes of extraction buffer ( $25 \mathrm{mM}$ sodium acetate buffer, $5 \mathrm{mM}$ L-Cys and 0.3 mM PMSF, pH 5.0) for $2 \mathrm{~min}$. The samples were then centrifuged at $10,000 \times g$ for $20 \mathrm{~min}$ to obtain a crude enzyme solution, whose $\mathrm{pH}$ was adjusted to 3.0 using $1 \mathrm{M} \mathrm{HCl}$. Next, the solution was incubated at $30{ }^{\circ} \mathrm{C}$ for $10 \mathrm{~min}$, and then centrifuged at $12,000 \times g$ for $20 \mathrm{~min}$ immediately after adjusting the $\mathrm{pH}$ to 5.8-6.0 using $1 \mathrm{M} \mathrm{NaOH}$. The supernatant was obtained and then salted out with $80 \%$ ammonium sulfate, and centrifuged at $10,000 \times g$ for $20 \mathrm{~min}$. Next, the sediment was collected and dialyzed against the phosphate buffer. The dialysis sample was concentrated using an Amicon Ultra-15 tube, and then passed through DEAE Sephacel, Sephacryl S-100, SP-Spharose FF, and Con A-Sepharose affinity chromatography columns. During purification, the hydrolytic activity of Z-Phe-Arg-MCA fluorescent substrate was monitored, and the active peaks were collected, concentrated, and stored at $-80^{\circ} \mathrm{C}$. CAT activity was determined using the method of Wang et al. [16], with Z-Phe-Arg-MCA as the substrate. One unit of enzyme activity was defined as the amount of activity that released $1 \mathrm{nmol}$ of $\mathrm{AMC}$ per min at $\mathrm{pH} 5.8$ and $37^{\circ} \mathrm{C}$.

\subsubsection{Incubation of MPs with Purified CAT}

MPs extracted from 0 day samples were used to investigate the role of CAT in the degradation of MPs in vitro. MPs extracted from $0 \mathrm{~d}$ samples were set as the $0 \mathrm{~h}$ sample, and were diluted to a final concentration of $2.0 \mathrm{mg} / \mathrm{mL}$. Then, fractions of MPs were incubated with CAT (25 U/mg of MPs) in incubation buffer $(10 \mathrm{mM}$ Tris- $\mathrm{HCl}$ and $5 \mathrm{mM}$ EDTA, pH 5.8) at 4, 20, and $37^{\circ} \mathrm{C}$ for $10 \mathrm{~h}$, respectively). MPs incubated without CAT were set as control (C). After $10 \mathrm{~h}$, the incubation was stopped by the addition of an equal volume of sampling treatment buffer $(30 \mathrm{mM}$ Tris- $\mathrm{HCl}, 3 \mathrm{mM}$ EDTA, 3\% SDS, $20 \%$ glycerol, $8 \%$ 2-mercaptoethanol, and $0.04 \%$ bromophenol blue, $\mathrm{pH} 8.0$ ). Samples were immediately denatured at $100{ }^{\circ} \mathrm{C}$ for $5 \mathrm{~min}$, and then stored at $-80^{\circ} \mathrm{C}$ for SDS-PAGE and western blotting.

\subsection{SDS-PAGE and Western Blotting}

Proteins were resolved with SDS-PAGE, and western blotting was conducted as described by Carlson et al. [17], with some modification. A 5\% polyacrylamide slab separating gel, without a stacking gel, was used to examine the changes in titin and nebulin integrity. For 5\% gels, $70 \mu \mathrm{g}$ of MPs samples were loaded per lane, and run at a constant current of $4.5 \mathrm{~mA}$ per gel for $15 \mathrm{~h}$ using the Bio-Rad Min-Protean II system (Bio-Rad Laboratories, Hercules, CA, USA). Conversely, 10\% and $12.5 \%$ polyacrylamide separating gels with a $5 \%$ polyacrylamide stacking gel were used to monitor the changes in $\alpha$-actinin, desmin, and troponin-T. MPs samples $(40 \mu \mathrm{g})$ were loaded per well to detect $\alpha$-actinin and desmin, whereas $20 \mu \mathrm{g}$ were used for troponin-T. All samples were run at a constant voltage of $80 \mathrm{~V}$ for stacking gels, and $100 \mathrm{~V}$ for separating gels at room temperature $\left(25^{\circ} \mathrm{C}\right)$. Triplicate gels were run, and the running buffer contained $25 \mathrm{mM}$ Tris, $192 \mathrm{mM}$ glycine, and 0.1\% SDS. After electrophoresis, gels were either stained for the examination of all protein bands, or transferred by polyvinylidene difluoride (PVDF, Bio-Rad Laboratories, Hercules, CA, USA) membranes for western blotting. Gels were stained for $6 \mathrm{~h}$ with 0.1\% Coomassie Brilliant Blue R-250 (w/v), 40\% ethanol (v/v), and $7 \%$ glacial acetic acid $(v / v)$. After staining, the same solution without Coomassie Brilliant Blue R-250 was used to destain the gels. Gels for western blotting were immediately transferred to PVDF membranes using the Bio-Rad Min-Protean II system at $90 \mathrm{~V}$ for $2 \mathrm{~h}$ for $\alpha$-actinin, $80 \mathrm{~V}$ for $1 \mathrm{~h}$ for desmin, and $70 \mathrm{~V}$ for $1 \mathrm{~h}$ for troponin-T, respectively. The transferring buffer contained $25 \mathrm{mM}$ Tris, $192 \mathrm{mM}$ glycine, and 10\% methanol (v/v). The electro-blotted membranes were then incubated at $4^{\circ} \mathrm{C}$ for $12 \mathrm{~h}$ in TTBS blocking buffer 
(0.05\% TWEEN $20(w / v), 20 \mathrm{mM}$ Tris, $137 \mathrm{mM} \mathrm{NaCl}, 5 \mathrm{mM} \mathrm{KCl}$, and 5\% skim milk (w/v)). After blocking, the membranes were then incubated with mouseanti- $\alpha$-acitinin monoclonal antibody (Abcam, Cambridge, UK) at a dilution of 1:250, mouse anti-desmin monoclonal antibody diluted 1:400 (Sigma-Aldrich, Milwaukee, WI, USA), and mouse anti-troponin-T monoclonal antibody at 1:500 (Sigma-Aldrich, Milwaukee, WI, USA), respectively. After three washes with TTBS buffer for $10 \mathrm{~min}$, the membranes were incubated with goat anti-mouse IgG horseradish peroxidase, conjugated affinity purified secondary antibody at a dilution of 1:5000 for $\alpha$-actinin (Abcam, Cambridge, UK), 1:5000 for desmin (SigmaAldrich, Milwaukee, WI, USA), and 1:10,000 for troponin-T (Sigma-Aldrich, Milwaukee, WI, USA), respectively. Membranes were rinsed thrice in TTBS buffer for 10 min before detection. A chemiluminescent detection system (GT-800F EPSON) was used to detect the immunoreactive protein bands, and the densities of targeted bands were analyzed by Quantity One software (Bio-Rad Laboratories).

\subsection{Statistical Analysis}

The experiments were performed in triplicate. The data were analyzed using a Statistical Analysis System (SAS Institute Inc., Cary, NC, USA). One-way ANOVA with Duncan's multiple range test was performed to measure the significant differences between samples $(p<0.05)$.

\section{Result and Discussion}

The tenderization of meat is a complex interaction of biochemical processes, among which, protein degradation by endogenous enzymes plays a pivotal role $[5,6]$. The proteolysis of key skeletal and costamere MPs, such as titin, nebulin, $\alpha$-actinin, desmin, and troponin-T, has been reported to be related to the tenderness of aged meat [18].

\subsection{Titin and Nebulin}

Titin (approximately $3000 \mathrm{kDa}$ ) and nebulin (approximately $800 \mathrm{kDa}$ ), anchoring one of their ends to the Z-line, are considered to be important contributors to myofibril integrity and meat tenderness [19-21]. The effect of CAT on hydrolysis of titin and nebulin in vivo and in vitro is shown in Figure 1 . For the 0 day samples, a major band for intact titin (T1) was observed. After 1 day postmortem, a major band for T1 degradation was observed, marked as T2 (approximately $2400 \mathrm{kDa}$ ), which was in accordance with the results reported by Taylor et al. [18]. Nevertheless, there was no observable difference between the various postmortem aging times. Regarding the T2 bands at 1, 3, 7, and 14 day postmortem, no obvious difference $(p>0.05)$ was found between the control and samples treated with CATI. In contrast to that of titin, the intensity of the nebulin band decreased $(p<0.05)$ as postmortem aging time increased. In particular, the intact nebulin band had nearly disappeared after 7 day postmortem. However, no obvious changes were found between the control and samples treated with CATI during the postmortem. These results indicated that CAT had no effect on the degradation of titin and nebulin during postmortem aging.

Figure 1c shows the results of purified MPs incubated with CAT at 4,20 , and $37^{\circ} \mathrm{C}$ for $10 \mathrm{~h}$. There were no notable changes $(p>0.05)$ in the band for both titin and nebulin between unincubated MPs and control samples. In addition, T1 was degraded to T2 after being incubated with CAT, and the intensity of the band for T1 was gradually decreased $(p<0.05)$ with increasing temperature. At $37^{\circ} \mathrm{C}, \mathrm{T} 1$ was totally degraded by CAT. Similar to titin, obvious differences $(p<0.05)$ in nebulin were observed between the control and samples incubated with CAT. Besides, it could be also found that the extent of nebulin degradation was increased $(p<0.05)$ with increasing temperature. The different results between in vivo and in vitro experiments might be due to the different temperatures. It is known that enzyme activity increases with increasing temperature, and as such, the lower temperature might be one factor resulting in the resistance to the degradation of titin and nebulin in vivo. 

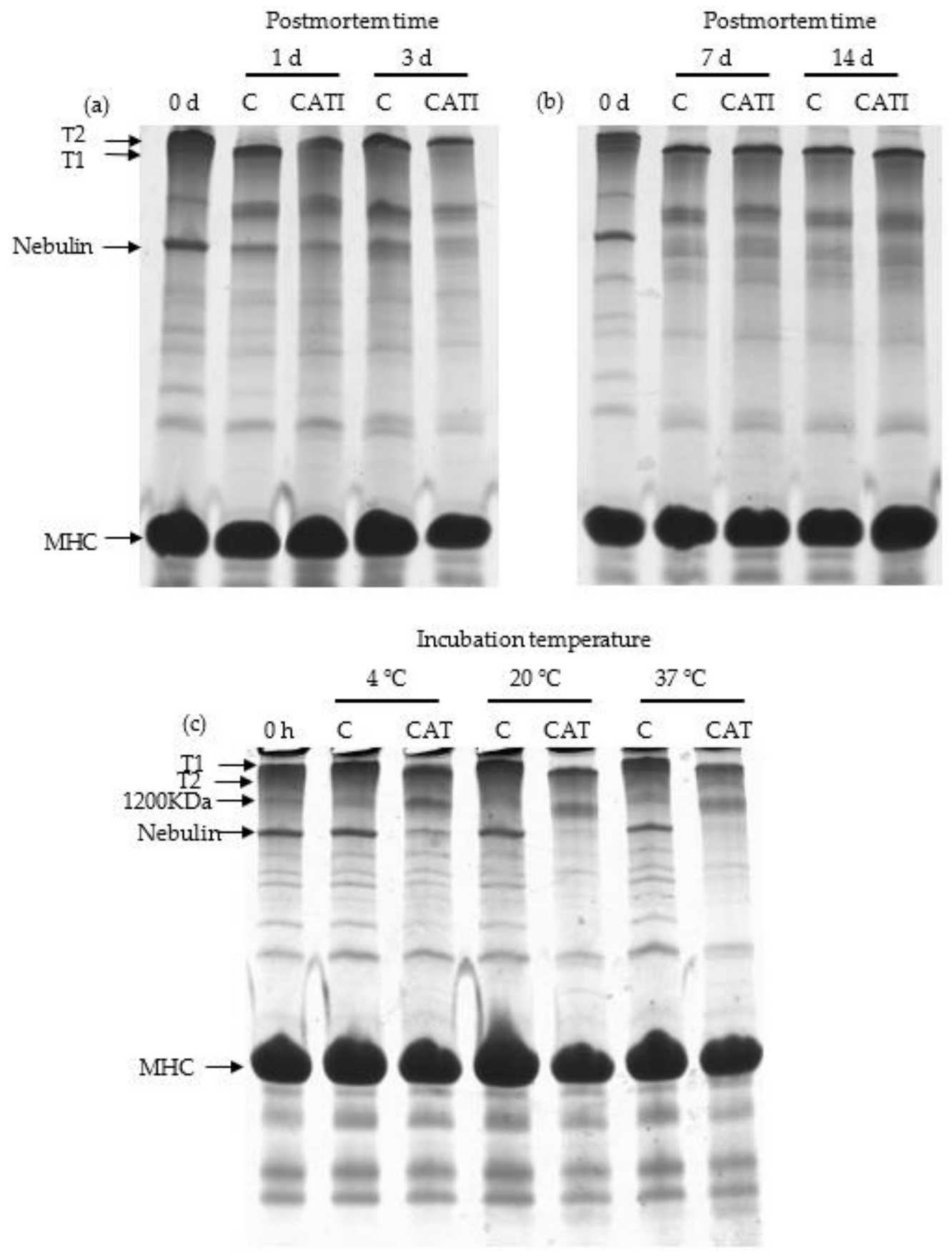

Figure 1. SDS-PAGE patterns of Coomassie-stained 5\% continuous polyacrylamide gel, indicating the degradation of titin and nebulin by cathepsin $\mathrm{L}$ in vivo and in vitro. (a) Samples treated with cathepsin $\mathrm{L}$ inhibitor for 0,1 , and 3 day postmortem at $4{ }^{\circ} \mathrm{C}$ in vivo; (b) samples treated with cathepsin $\mathrm{L}$ inhibitor for 0,7 , and 14 day postmortem at $4{ }^{\circ} \mathrm{C}$ in vivo; (c) samples incubated with cathepsin $\mathrm{L}$ for $10 \mathrm{~h}$ at 4,20 , and $37^{\circ} \mathrm{C}$ in vitro. Abbreviations are as follows: $\mathrm{T} 1=$ intact titin; $\mathrm{T} 2=$ degradation product of intact titin; $\mathrm{MHC}=$ myosin heavy chain; $\mathrm{C}=$ control; $\mathrm{CAT}=$ cathepsin $\mathrm{L} ; \mathrm{CATI}=$ sample incubated with cathepsin $\mathrm{L}$ inhibitor.

\section{2. $\alpha$-Actinin}

$\alpha$-Actinin is crucial for connecting together actin filaments from adjacent sarcomeres, and forming the Z-disk, and then contributing to proper muscle physiology [22]. Changes of $\alpha$-actinin caused by CAT in vitro and in vivo were investigated (Figure 2 ). As shown in Figure $2 a, b$, proteolytic fragments of $\alpha$-actinin were not detected in all bands when using anti- $\alpha$-actinin monoclonal antibody in vivo. This was in accordance with the study of 
Ho et al., who revealed that little $\alpha$-actinin change was detected using western blot analysis through $28 \mathrm{~d}$ of bovine longissimus muscle postmortem aging [23]. Also, the degradation fraction of $\alpha$-actinin was not detected in all samples in vitro (Figure $2 c$ ). Taken together, CAT had no effect on the degradation of $\alpha$-actinin both in vivo and in vitro.

\subsection{Desmin}

Desmin comprises mostly attachments of Z- to Z-line, and is likely a key substrate that determines meat tenderness [19]. The effect of CAT on the degradation of desmin in vivo is shown in Figure $3 a, b$. In contrast to $\alpha$-actinin, compared with the 0 day sample, the degradation fragment of desmin was observed during postmortem aging. For the control sample, one new faint band and two new faint bands were observed at 1 day postmortem and after 3 day postmortem, respectively. This was in agreement with the study of Hwan, which indicated that desmin was easily degraded at $4{ }^{\circ} \mathrm{C}$ in bovine semitendinosus muscle during the aging process [24]. In addition, the intensity of the new band was increased $(p<0.05)$ with an increased postmortem time. Similarly, two new faint bands were observed, whose intensity was increased $(p<0.05)$ with increased postmortem time for samples treated with CATI. Moreover, it was obvious that the intensity of the new band for samples treated with CATI was higher $(p<0.05)$ than that of the control. These results indicated that CAT participated in the degradation of desmin during postmortem aging.

The effect of CAT on the degradation of desmin in vitro is shown in Figure 3c. Compared with the 0 day sample, the degradation fragment of desmin was not detected in the control sample at 4,20 , and $37^{\circ} \mathrm{C}$, indicating that temperature did not affect the degradation of desmin. In addition, compared with the control sample, the degradation fragment of desmin was also not detected in the CAT-treated samples, regardless of incubation temperature. These results indicated that CAT did not participate in the degradation of desmin in vitro. 

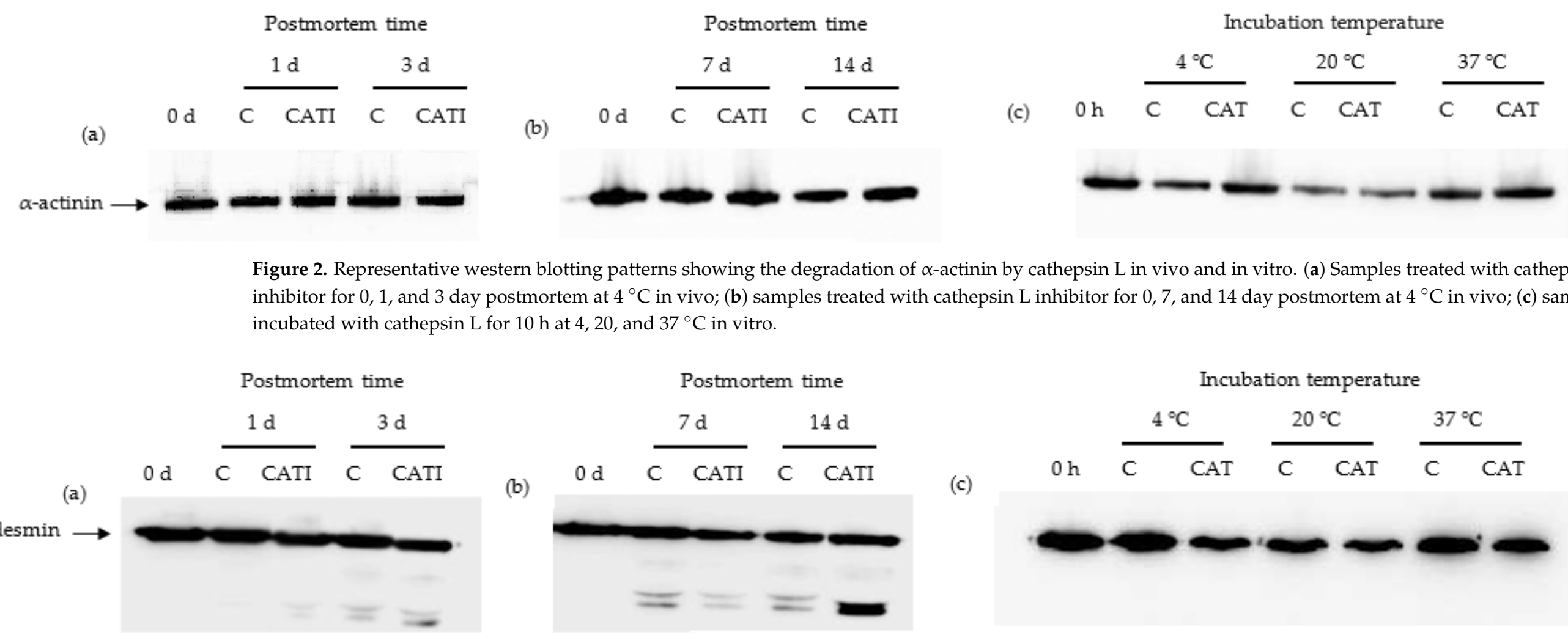

Figure 3. Representative western blotting patterns showing the degradation of desmin by cathepsin $\mathrm{L}$ in vivo and in vitro. (a) Samples treated with cathepsin $\mathrm{L}$ inhibitor for 0,1 , and 3 day postmortem at $4{ }^{\circ} \mathrm{C}$ in vivo; (b) samples treated with cathepsin L inhibitor for 0,7 , and 14 day postmortem at $4{ }^{\circ} \mathrm{C}$ in vivo; (c) samples incubated with cathepsin $\mathrm{L}$ for $10 \mathrm{~h}$ at 4,20 , and $37^{\circ} \mathrm{C}$ in vitro. 


\subsection{Troponin-T}

Troponin- $\mathrm{T}$ is the tropomyosin-binding component of the troponin complex, and is generally considered to be the most proteolytically sensitive subunit of the troponin molecule [25]. Degradation of troponin-T is considered to be an indicator of meat aging and tenderization [26,27], as denoted by the appearance of the main proteolysis fragments of 28-32 kDa [12,27-29]. Representative western blotting patterns are shown in Figure 4a,b, and the lanes indicate that the anti-troponin-T monoclonal antibody could clearly and strongly recognize the troponin-T bands. At 0 day postmortem, the 28, 30, and $32 \mathrm{kDa}$ bands were detected, which might be mainly due to the part degradation of troponin- $\mathrm{T}$ in the extracting process of samples. Compared with the 0 day sample, a new $26 \mathrm{kDa}$ band was detected during postmortem aging from 1 day to 14 day. In addition, the intensity of 26-32 kDa bands was gradually increased $(p<0.05)$ with increased postmortem time for both control and CATI-treated samples, accompanied by a decrease in the intensity of troponin-T band. In addition, there was no obvious change $(p>0.05)$ between the control and CATI-treated samples at 1 day and 3 day postmortem. Nevertheless, compared with the control, the degradation of troponin-T treated with CATI was more obvious after 7 day postmortem, and the intensity of 26-32 kDa bands was higher than that of the control samples. These results indicated that CAT participated in the degradation of troponin-T during postmortem aging.

The effect of CAT on the degradation of troponin-T in vitro is shown in Figure 4c. At $4{ }^{\circ} \mathrm{C}$, there was no observable difference $(p>0.05)$ between control and CAT-treated samples. At $20^{\circ} \mathrm{C}$, the 28,30 , and $32 \mathrm{kDa}$ bands were detected in the control sample, whereas a new $26 \mathrm{kDa}$ band was detected in the CAT-treated sample. Furthermore, the intensity of degraded fraction bands in the CAT-treated sample was higher $(p<0.05)$ than that in the control sample. At $37^{\circ} \mathrm{C}$, only 26, 28, and $30 \mathrm{kDa}$ bands were detected in the CAT-treated sample. Similarly, the intensity of bands in the CAT-treated sample was higher $(p<0.05)$ than that in the control sample. These results indicated that CAT affected the degradation of troponin- $T$ in vitro, and the extent of the degradation was affected by incubation temperature. This was in accordance with the results of previous studies showing that cathepsin L could hydrolyze troponin- $\mathrm{T}$ from rabbit or carp myofibril protein at 20 and $37^{\circ} \mathrm{C}[11,30]$. In summary, CAT participated in the degradation of troponin-T both in vitro and in vivo.

Based on the results of the degradation of titin, nebulin, $\alpha$-actinin, desmin, and tropinin- $T$ in in vitro and in vivo experiments, we could conclude that CAT had an important role in degrading MPs in vivo and in vitro, and thus, might contribute to meat tenderization, which was confirmed by the results of the shear force test, as shown in the Supplementary Materials. 


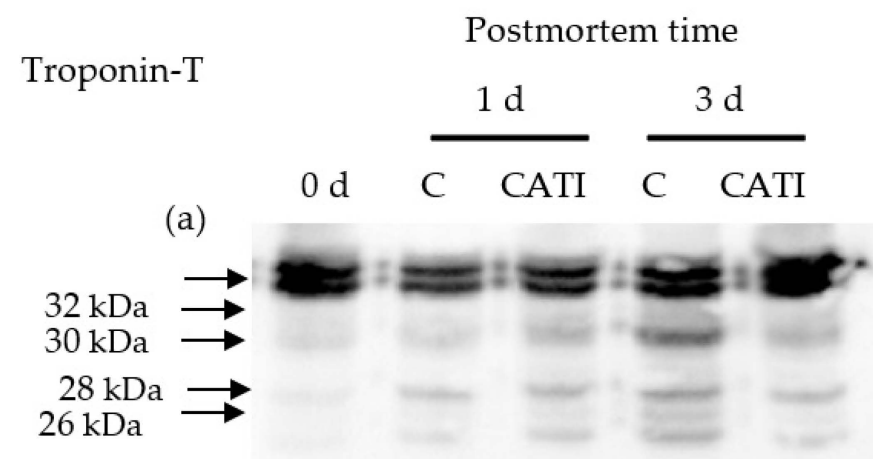

(b)

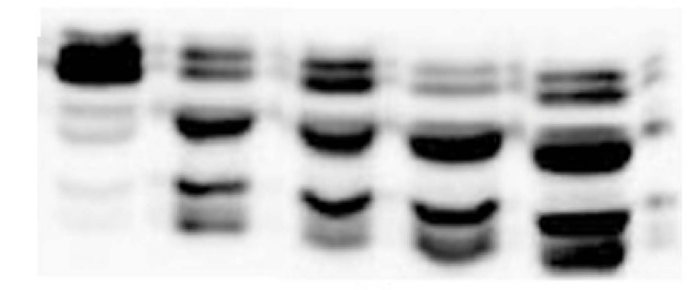

Postmortem time

$7 \mathrm{~d}$

$\frac{7 \mathrm{~d}}{\mathrm{C} \text { CATI }} \frac{14 \mathrm{~d}}{\mathrm{C} \text { CATI }}$

(c)

Incubation temperature

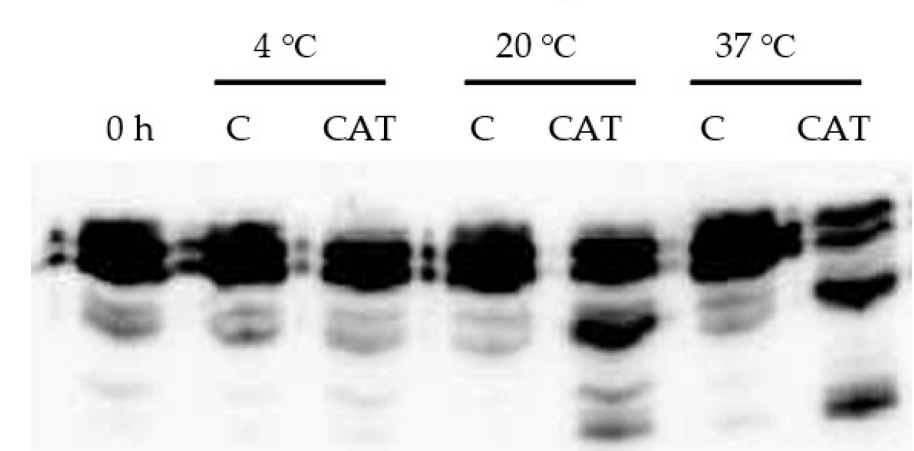

Figure 4. Representative western blotting patterns showing the degradation of troponin-T by cathepsin $\mathrm{L}$ in vivo and in vitro. (a) Samples treated with cathepsin $\mathrm{L}$ inhibitor for $0,1,3$ day postmortem at $4{ }^{\circ} \mathrm{C}$ in vivo; (b) samples treated with cathepsin $\mathrm{L}$ inhibitor for $0,7,14$ day postmortem at $4{ }^{\circ} \mathrm{C}$ in vivo; (c) samples incubated with cathepsin $\mathrm{L}$ for $10 \mathrm{~h}$ at 4,20 , and $37^{\circ} \mathrm{C}$ in vitro. 


\section{Conclusions}

This study demonstrated that CAT participated in the degradation of MPs both in vivo and in vitro. CAT caused the degradation of titin and nebulin in vitro, the extent of which increased with increased incubation temperature, but had no effect on the degradation of these MPs in vivo. In addition, compared with the control, the presence of CATI caused further degradation of desmin in vivo, the extent of which was increased with increased postmortem aging time, whereas no degradation of desmin was observed in the presence of CAT in vitro, regardless of incubation time. For troponin-T, compared with the control, CATI did not cause an obvious degradation of troponin-T at 1 and $3 \mathrm{~d}$ postmortem, but exerted more obvious degradation after 7 day postmortem in vivo. In addition, the presence of CAT caused further degradation of troponin-T in vitro, and the extent of the degradation was increased with increased incubation temperature. Temperature might be a critical factor causing the difference between in vivo and in vitro results. Therefore, the results might provide a reference for understanding the role of CAT in MPs degradation and meat tenderization.

Supplementary Materials: The following supporting information can be downloaded at: https: / /www.mdpi.com/article/10.3390/foods11040613/s1, Figure S1: Warner-Bratzler shear force of beef treated with cathepsin $\mathrm{L}$ in different incubated temperature.

Author Contributions: Conceptualization, X.G. and B.C.; methodology, B.C.; software, X.G.; validation, B.C. and X.G.; formal analysis, Y.Z.; investigation, B.C.; resources, X.M.; data curation, B.C.; writing-original draft preparation, X.G. and B.C.; writing-review and editing, X.G.; visualization, X.G.; supervision, X.M.; project administration, X.G.; funding acquisition, X.G. and B.C. All authors have read and agreed to the published version of the manuscript.

Funding: This research was funded by Natural science research foundation of colleges and universities of Jiangsu Province [20KJB550010] and Yangzhou University Science and Technology Innovation Projects [137012527]. And the APC was funded by Natural science research foundation of colleges and universities of Jiangsu Province, grant number [20KJB550010].

Institutional Review Board Statement: This paper should not be required the approval from Ethics Committee or Institutional Review Board.

Data Availability Statement: The data that support the findings of this study are available on request from the corresponding author.

Acknowledgments: This research was supported by Yangzhou University Science and Technology Innovation Projects (137012527), and the Natural Science Research Foundation of Colleges and Universities of Jiangsu Province (20KJB550010).

Conflicts of Interest: The authors declare no conflict of interest.

\section{References}

1. Danga, D.S.; Buhlera, J.F.; Davisa, H.T.; Thornton, K.J.; Schefflerc, T.L.; Matarneh, S.K. Inhibition of mitochondrial calcium uniporter enhances postmortem proteolysis and tenderness in beef cattle. Meat Sci. 2020, 162, 108039. [CrossRef] [PubMed]

2. Demir, H.; Elik, S.; Sezer, Y.E. Effect of ultrasonication and vacuum impregnation pretreatments on the quality of beef marinated in onion juice a natural meat tenderizer. Food Sci. Technol. Int. 2021, 28, 10820132211012919. [CrossRef] [PubMed]

3. Warner, R.; Wheeler, T.L.; Ha, M.; Li, X.; Zhang, W.G. Meat tenderness: Advances in biology, biochemistry, molecular mechanisms and new technologies. Meat Sci. 2021, 185, 108657. [CrossRef]

4. Chen, L.; Feng, X.C.; Zhang, Y.Y.; Liu, X.B.; Zhang, W.G.; Li, C.B.; Ullah, N.; Xu, X.L.; Zhou, G.H. Effects of ultrasonic processing on caspase-3, calpain expression and myofibrillar structure of chicken during post-mortem ageing. Food Chem. 2015, 177, $280-287$. [CrossRef] [PubMed]

5. Huff-Lonergan, E.; Zhang, W.G.; Lonergan, S.M. Biochemistry of postmortem muscle-lessons on mechanisms of meat tenderization. Meat Sci. 2010, 86, 184-195. [CrossRef] [PubMed]

6. Koohmaraie, M.; Geesink, G.H. Contribution of postmortem muscle biochemistry to the delivery of consistent meat quality with particular focus on the calpain system. Meat Sci. 2006, 74, 34-43. [CrossRef]

7. Bhat, Z.F.; Morton, J.D.; Mason, S.L.; Bekhit, A. Role of calpain system in meat tenderness: A review. Food Sci. Hum. Wellness 2018, 7, 196-204. [CrossRef] 
8. Bechet, D.; Tassa, A.; Taillandier, D.; Combaret, L.; Attaix, D. Lysosomal proteolysis in skeletal muscle. Int. J. Biochem. Cell Biol. 2005, 37, 2098-2114. [CrossRef]

9. Uytterhaegen, L.; Claeys, E.; Demeyer, D. Effects of exogenous protease effectors on beef tenderness development and myofibrillar degradation and solubility. J. Anim. Sci. 1994, 72, 1209-1223. [CrossRef]

10. Ouali, A.; Garrel, N.; Obled, A.; Deval, C.; Valin, C.; Penny, I.F. Comparative action of cathepsins D, B, H, L and of a new lysosomal cysteine proteinase on rabbit myofibrils. Meat Sci. 1987, 19, 83-100. [CrossRef]

11. Matsukura, U.; Okitani, A.; Nishimuro, T.; Kato, H. Mode of degradation of myofibrillar proteins by an endogenous protease, cathepsin L. Biochim. Biophys. Acta 1981, 662, 41-47. [CrossRef]

12. Mikami, M.; Whiting, A.H.; Taylor, M.A.; Maciewicz, R.A.; Etherington, D.J. Degradation of myofibrils from rabbit, chicken and beef by cathepsin L and lysosomal lysates. Meat Sci. 1987, 21, 81-97. [CrossRef]

13. Koohmaraie, M.; Whipple, G.; Kretchmar, D.H.; Crouse, J.D.; Mersmann, H.J. Postmortem proteolysis in longissimus muscle from beef, lamb and pork carcases. J. Anim. Sci. 1991, 69, 617-624. [CrossRef] [PubMed]

14. Huang, M.; Huang, F.; Xu, X.L.; Zhou, G.H. Influence of caspase3 selective inhibitor on proteolysis of chicken skeletal muscle proteins during post mortem aging. Food Chem. 2009, 115, 181-186. [CrossRef]

15. Li, S.; Zhou, X.; Zhang, N.; Liu, H.; Ma, C. Purification and characterisation of cathepsin L2 from dorsal muscle of silver carp (Hypophthalmichthys molitrix). Food Chem. 2008, 111, 879-886. [CrossRef]

16. Wang, R.; Peng, Z.; Hui, T.; Wang, F.; Yao, Y.; Zhang, Y.; Zhou, G. Potential use of crude extracts from Alaska Pollock muscle as meat tenderizer. CyTA-J. Food 2008, 11, 50-59. [CrossRef]

17. Carlson, K.B.; Prusa, K.J.; Fedler, C.A.; Steadham, E.M.; Lonergan, S.M. Postmortem protein degradation is a key contributor to fresh pork loin tenderness. J. Anim. Sci. 2017, 95, 1574. [CrossRef]

18. Taylor, R.G.; Geesink, G.H.; Thompson, V.F.; Koohmaraie, M.; Goll, D.E. Is z-disk degradation responsible for postmortem tenderization. J. Anim. Sci. 1995, 73, 1351-1367. [CrossRef]

19. Lu, X.; Zhang, Y.M.; Xu, B.C.; Zhu, L.X.; Luo, X. Protein degradation and structure changes of beef muscle during superchilled storage. Meat Sci. 2020, 168, 108180. [CrossRef]

20. Fritz, J.D.; Mitchell, M.C.; Marsh, B.B.; Greaser, M.L. Titin content of beef in relation to tenderness. Meat Sci. 1993, 33, 41-50. [CrossRef]

21. Huff-Lonergan, E.; Robson, R.M. Effects of postmortem aging time, animal age, and sex on degradation of titin and nebulin in bovine longissimus muscle. J. Anim. Sci. 1995, 73, 1064-1073. [CrossRef] [PubMed]

22. Baldassarri, V.; Salucci, S.; Ferri, P.; Falcieri, E.; Burattini, S. The role of $\alpha$-actinin in z-disks assembly: A morphological point of view. Microscopie 2012, 18, 37-44.

23. Ho, C.Y.; Stromer, M.H.; Robson, R.M. Effect of electrical stimulation on postmortem titin, nebulin, desmin, and troponin-t degradation and ultrastructural changes in bovine longissimus muscle. J. Anim. Sci. 1996, 74, 1563-1575. [CrossRef] [PubMed]

24. Hwan, S.; Bandman, E. Studies of desmin and $\alpha$-actinin degradation in bovine semitendinosus muscle. J. Food Sci. 1989, 54, 1426-1430. [CrossRef]

25. Greaser, M.L.; Gergely, J. Reconstitution of troponin activity from three protein components. J. Biol. Chem. 1971, 246, 4226-4233. [CrossRef]

26. Penny, I.F.; Nsfield, E. Relationship between toughness and troponin t in conditioned beef. Meat Sci. 1979, 3, 135-141. [CrossRef]

27. Harris, S.E.; Huff-Lonergan, E.; Lonergan, S.M.; Jones, W.R.; Rankins, D. Antioxidant status affects color stability and tenderness of calcium chloride-injected beef. J. Anim. Sci. 2001, 79, 666-677. [CrossRef] [PubMed]

28. Ho, C.Y.; Stromer, M.H.; Robson, R.M. Identification of the $30 \mathrm{kDa}$ polypeptide in post mortem skeletal muscle as a degradation product of troponin-T. Biochimie 1994, 76, 369-375. [CrossRef]

29. Ming, H.; Feng, H.; Mei, X.; Xu, X.; Zhou, G. The effect of active caspase-3 on degradation of chicken myofibrillar proteins and structure of myofibrils. Food Chem. 2011, 128, 22-27.

30. Yamashita, M.; Konagaya, S. Hydrolytic action of salmon cathepsins B and L to muscle structural proteins in respect of muscle softening. Nippon. Suisan Gakkaishi 1991, 57, 1917-1922. [CrossRef] 